\title{
บUsisersily
}

\section{'Hard to reach, but not out of reach': Barriers and facilitators to recruiting Black African and Black Caribbean men with prostate cancer and their partners into qualitative research}

Bamidele, O., McGarvey, H., Lagan, B. M., Chinegwundoh, F., Nasreen, A., \& McCaughan, E. (2018). 'Hard to reach, but not out of reach': Barriers and facilitators to recruiting Black African and Black Caribbean men with prostate cancer and their partners into qualitative research. European Journal of Cancer Care, 1-11.

[ECC12977]. https://doi.org/DOI: 10.1111/ecc.12977

Link to publication record in Ulster University Research Portal

Published in:

European Journal of Cancer Care

Publication Status:

Published online: 12/12/2018

DOI:

DOI: $10.1111 /$ ecc. 12977

\section{Document Version}

Publisher's PDF, also known as Version of record

\section{General rights}

Copyright for the publications made accessible via Ulster University's Research Portal is retained by the author(s) and / or other copyright owners and it is a condition of accessing these publications that users recognise and abide by the legal requirements associated with these rights.

\section{Take down policy}

The Research Portal is Ulster University's institutional repository that provides access to Ulster's research outputs. Every effort has been made to ensure that content in the Research Portal does not infringe any person's rights, or applicable UK laws. If you discover content in the Research Portal that you believe breaches copyright or violates any law, please contact pure-support@ulster.ac.uk. 


\title{
"Hard to reach, but not out of reach": Barriers and facilitators to recruiting Black African and Black Caribbean men with prostate cancer and their partners into qualitative research
}

\author{
Olufikayo O. Bamidele ${ }^{1}$ (D) | Helen E. McGarvey ${ }^{2}$ (D) | Briege M. Lagan ${ }^{1}$ (D) | \\ Frank Chinegwundoh ${ }^{3,4}$ | Nasreen Ali $^{5}$ | Eilis McCaughan ${ }^{6}$
}

${ }^{1}$ Institute of Nursing and Health

Research, Ulster University, Jordanstown,

UK

${ }^{2}$ School of Nursing, Ulster University, Londonderry, UK

${ }^{3}$ Barts Health NHS Trust, London, UK

${ }^{4}$ School of Health Sciences: City, University of London, London, UK

${ }^{5}$ Institute for Health Research, University of Bedfordshire, Luton, UK

${ }^{6}$ Institute of Nursing and Health

Research, Ulster University, Coleraine, UK

Correspondence

Olufikayo O. Bamidele, Institute of Nursing and Health Research, Ulster University, Jordanstown, UK.

Email: Bamidele-O@ulster.ac.uk

Funding information

The current study is being funded by an Ulster University Vice-Chancellor's Research Scholarship to OB for her $\mathrm{PhD}$.

\begin{abstract}
Access and recruitment barriers may have contributed to the underrepresentation of Black African/Caribbean men and their partners in current psychosocial research related to prostate cancer survivors. Whilst some studies have explored recruitment barriers and facilitators from participants' perspectives, little is known from researchers' point of view. This paper aimed to address this gap in the literature. Recruitment strategies included the following: cancer support groups, researchers' networks, media advertisement, religious organisations, National Health Service hospitals and snowball sampling. Thirty-six eligible participants (men $=25$, partners $=11$ ) were recruited into the study. Recruitment barriers comprised of gate-keeping and advertisement issues and the stigma associated with prostate cancer disclosure. Facilitators which aided recruitment included collaborating with National Health Service hospitals, snowball sampling, flexible data collection, building rapport with participants to gain their trust and researcher's attributes. Findings highlight that "hard to reach" Black African/Caribbean populations may be more accessible if researchers adopt flexible but strategic and culturally sensitive recruitment approaches. Such approaches should consider perceptions of stigma associated with prostate cancer within these communities and the influence gatekeepers can have in controlling access to potential participants. Increased engagement with healthcare professionals and gatekeepers could facilitate better access to Black African/Caribbean populations so that their voices can be heard and their specific needs addressed within the healthcare agenda.
\end{abstract}

KEYWORDS

African caribbean, Black African, men, partners, prostate cancer, recruitment

\section{1 | INTRODUCTION}

Prostate cancer ( $\mathrm{CaP}$ ) affects one in four Black African (BA) and Black Caribbean (BC) men earlier in life and in more aggressive forms

${ }^{\dagger}$ Member of the Most Excellent Order of the British Empire. compared with one in eight Caucasian men (Jones \& Chinegwundoh, 2014). However, it appears that access and recruitment barriers may have contributed to the underrepresentation of $B A$ and $B C$ men and their partners in current psychosocial research related to $\mathrm{CaP}$ survivors (Bamidele, McGarvey, et al., 2017) as these have mostly involved Caucasian (McCaughan, McKenna, McSorley, \& Parahoo, 
2015; O'Shaughnessy, Ireland, Pelentsov, Thomas, \& Esterman, 2013; Speer, Tucker, McPhillips, \& Peters, 2017) and some African American (AA) (Rivers et al., 2011, 2012) groups.

The National Institute for Health and Care Excellence (NICE, 2015) recommends the provision of psychosocial interventions to complement clinical aids in supporting men after CaP treatment. Given the existing ethnic diversity of the UK population (Office for National Statistics [ONS], 2012), cultural disparities in CaP experiences and support needs as influenced by their specific socio-cultural context should be considered when developing psychosocial interventions for men with $\mathrm{CaP}$ and their partners (Hosseinpoor, Williams, Itani, \& Chatterji, 2012; Marmot et al., 2010; Pinder, Ferguson, \& Moller, 2016). Qualitative researchers in particular, have a role in helping to engage under-studied $B A$ and $B C$ groups in in-depth research to inform the provision of culturally sensitive psychosocial support for them after CaP treatment.

Amidst suggestions that BA and BC groups are often "hard to reach" (Mulugeta, Williamson, Monks, Hack, \& Beaver, 2017) because they cannot be easily accessed by researchers (Sydor, 2013), there is a dearth of literature reporting researchers' perspectives on the barriers and facilitators to recruiting $\mathrm{BA} / \mathrm{BC}$ men and their partners into qualitative research on CaP survivorship. Current available evidence has focused on participants' perspectives and clinical research on CaP (Toms, Cahill, George, \& Hemelrijck, 2016). Wider evidence relating to other "hard to reach" groups further highlights that participants' opinions of the topic being investigated (Jones et al., 2014), and the nature of research being conducted (e.g., experimental studies) may also have an impact on recruitment outcomes (Mamotte \& Wassenaar, 2017; Newington \& Metcalfe, 2014). These suggest the need for qualitative researchers to be aware (through other researchers' experiences) of strategies they can adopt to maximise recruitment for their studies.

In light of the above, this paper aims to: (a) report the strategies used to recruit $\mathrm{BA}$ and $\mathrm{BC}$ men with $\mathrm{CaP}$ and their partners into a grounded theory study; (b) discuss the barriers and facilitators to recruitment; and (c) provide useful suggestions for other researchers seeking to engage similar groups and other "hard to reach" populations in their studies.

\section{METHODS}

\subsection{The study}

The main aim of the grounded theory study was to explore the experiences of BA/BC men and their partners and their psychosocial needs after CaP treatment and how best to address them. Participants were recruited in England which has a high BA and BC populations (ONS, 2012). Prior to theoretical sampling which is ideally used in grounded theory studies, convenience and snowball sampling were used to identify participants to generate the initial data. Upon receipt of ethical approvals, recruitment of eligible participants occurred between October 2016 and March 2018. Participants were provided with contact details of relevant support services if required. Upon providing written informed consent,

\begin{tabular}{|c|c|c|}
\hline & Inclusion & Exclusion \\
\hline \multirow[t]{5}{*}{ Men } & $\mathrm{BA}$ or $\mathrm{BC}$ ethnic origin & $\begin{array}{l}\mathrm{BA} / \mathrm{BC} \text { men receiving palliative care (because it } \\
\text { was perceived that their needs may be beyond } \\
\text { the scope of the study) }\end{array}$ \\
\hline & $\begin{array}{l}\text { Undergone at least } 3 \text { months } \\
\text { post active treatment for } \\
\text { CaP }\end{array}$ & \\
\hline & $\begin{array}{l}\text { Aged } 35 \text { years and above (BA/ } \\
\text { BC men may develop CaP } \\
\text { earlier in life compared to } \\
\text { men of other ethnic } \\
\text { populations) }\end{array}$ & \\
\hline & Resident in the UK & \\
\hline & $\begin{array}{l}\text { Able to read, understand and } \\
\text { speak English language }\end{array}$ & \\
\hline \multirow[t]{6}{*}{ Partners } & $\begin{array}{l}\text { In intimate or marital } \\
\text { relationship with a } \mathrm{BA} \text { or } \mathrm{BC} \\
\text { man who has undergone at } \\
\text { least three months post } \\
\text { active treatment for } \mathrm{CaP}\end{array}$ & $\begin{array}{l}\text { Partners of } \mathrm{BA} / \mathrm{BC} \text { men with } \mathrm{CaP} \text { receiving } \\
\text { palliative care (same as reason for excluding } \\
\text { the men) }\end{array}$ \\
\hline & Resident in the UK & \\
\hline & Aged 18 years and above & \\
\hline & $\begin{array}{l}\text { Able to read, understand and } \\
\text { speak English language }\end{array}$ & \\
\hline & Can be of any ethnic origin & \\
\hline & Can be of any gender & \\
\hline
\end{tabular}

TABLE 1 Inclusion and exclusion criteria for the study 
participants had the option to be interviewed either face-to-face, by Skype or telephone. The interviews, which were tape-recorded and lasted between 30 and 90 min, were conducted by the first author (OB) who is a BA woman in her mid-thirties. Where a man and his partner agreed to be interviewed, in an attempt to keep both engaged in the study, interviews where possible, were scheduled for the same date and mode. This also helped the researcher to manage her time and financial resources. The partners were interviewed separately.

\subsection{Study sample}

Three different sample groups were included in the study: (a) BA and $\mathrm{BC}$ men with $\mathrm{CaP}$; (b) partners of $\mathrm{BA}$ or $\mathrm{BC}$ men with $\mathrm{CaP}$; and (c) healthcare professionals (HCPs) within an uro-oncology team. This article focuses on the recruitment of $\mathrm{BA} / \mathrm{BC}$ men with $\mathrm{CaP}$ and their partners. Recruitment was guided by pre-defined inclusion and exclusion criteria (Table 1). Eligible partners were included irrespective of their gender or ethnicity (self-reported). Partners' inclusion was not dependent on their male partners with $\mathrm{CaP}$ participating in the study.

\section{3 | Recruitment strategies}

Although priority in qualitative research is focused more on obtaining rich and in-depth data, (Bonevski et al., 2014), it was considered essential to reduce the risk of under-recruitment which could jeopardise theoretical saturation (when emerging categories are fully conceptualised and no further data is required) crucial to the rigour and trustworthiness of this grounded theory study (Foley \& Timonen, 2015). Therefore, the research team projected (based on previous grounded theory studies e.g., Mulugeta et al., 2017) that approximately 30 men and partners inclusive, would provide the rich in-depth data required to achieve theoretical saturation. We also considered that the few previous related studies (Anderson, Marshall-Lucette, \& Webb, 2013; Gray, Fergus, \& Fitch, 2005; Nanton \& Dale, 2011) had mostly involved Jamaican men and no study was identified which included partners of BA/BC men with CaP. Thus, we decided to diversify recruitment strategies to enhance recruitment of a more heterogeneous sample of eligible BA/BC men and also partners into the study.

Ideas about recruitment were deliberated among the research team, explored with other researchers who have had success with recruiting Black men with $\mathrm{CaP}$ into their studies (e.g., Nanton \& Dale, 2011), and also discussed with a Patient Public Involvement (PPI) group. The PPI group consisted of a female uro-oncology nurse specialist, a male leader of a prostate cancer support group and a $\mathrm{BA}$ man with $\mathrm{CaP}$ in his early fifties. Potential recruitment strategies were identified which included cancer support groups, colleagues' and researchers' networks, media advertisement, religious organisations, National Health Service (NHS) hospital Trusts and snowball sampling via research participants.

\subsection{1 | Cancer support groups}

A total of 33 support groups which focused on Black and Minority Ethnic (BME) cancer survivors were identified and contacted by the researcher (OB) either by email or telephone. The nature and process of the study were clearly explained to a lead contact within each support group. Their role in helping to facilitate access to eligible members and the potential value of the research to their organisation and $B A / B C$ service users were also clarified to the support groups. The lead person or an identified gatekeeper at each support group was asked how best to access and recruit any eligible members for the study. A poster was developed by the research team to advertise the study at the support groups. Feedback from gatekeepers at support groups was invited as regards the suitability of the poster, especially in terms of content, language use and comprehensibility. In line with the approved study protocol, gatekeepers who were willing in the first instance were asked to discuss the study with interested eligible members. This was to try and help establish trust and develop a rapport with the potential participant (Anderson et al., 2009). If a member of the support group agreed, their contact details were passed on to the researcher (OB) for further discussion. Eligible potential participants were then sent an information pack detailing the purpose of the research, what their participation would involve and contact details of the researcher. Once a participant who was happy to take part returned his signed consent form, interview date, time and venue were agreed.

\subsection{2 | Colleagues' and researchers' network}

A network of colleagues and researchers who had previously published in related fields were contacted and asked to suggest possible avenues to explore recruitment. Any contacts who were aware of potential participants discussed the study with them initially and with their permission, forwarded their contact details to the researcher. The researcher then made direct contact with the potential participant and following consent, scheduled an interview.

\subsection{3 | Media advertisement}

Using a tailored media script, the study was advertised on two UKbased radio stations located in London and Birmingham and focused on BA and BC audiences. Radio presenters from both stations suggested appropriate presentation styles that they perceived would appeal to the Black population (e.g., having low background music and a Black male narrator). The advertisement ran on each of the two radio stations approximately eight times daily for a month and also on their websites, at a total cost of $£ 505$. Due to limited finances, it was not possible to extend the advert beyond a month or to other radio/TV stations or newspapers. 
TABLE 2 Recruitment strategies and outcomes

\begin{tabular}{|c|c|c|c|c|c|c|c|}
\hline Recruitment strategy & $\begin{array}{l}\text { Potential } \\
\text { contacts } \\
\text { received } \\
n\end{array}$ & $\begin{array}{l}\text { Successfully } \\
\text { contacted to } \\
\text { take part } \\
n(\%)\end{array}$ & $\begin{array}{l}\text { Identified as } \\
\text { ineligible } \\
n(\%)\end{array}$ & $\begin{array}{l}\text { Declined to } \\
\text { participate } \\
n(\%)\end{array}$ & $\begin{array}{l}\text { Men who } \\
\text { partici- } \\
\text { pated } \\
n(\%)\end{array}$ & $\begin{array}{l}\text { Partners who } \\
\text { participated } \\
n(\%)\end{array}$ & $\begin{array}{l}\text { Overall total } \\
\text { participants (men } \\
\text { and partners) } \\
n(\%)\end{array}$ \\
\hline NHS Trusts & 38 & $32(71)$ & $3^{a}(7)$ & $6^{\mathrm{b}}(13)$ & $20(80)$ & $3(27)$ & $23(64)$ \\
\hline $\begin{array}{l}\text { Snowballing using } \\
\text { recruited research } \\
\text { participants }\end{array}$ & 10 & $9(20)$ & - & - & $2(8)$ & $7(63)$ & $9(25)$ \\
\hline $\begin{array}{l}\text { Colleagues and } \\
\text { Researchers' } \\
\text { Networks }\end{array}$ & 3 & $3(7)$ & - & - & $2(8)$ & $1(9)$ & $3(8)$ \\
\hline Cancer support groups & 1 & $1^{\mathrm{a}}(2)$ & - & - & $1(4)$ & - & $1(3)$ \\
\hline Media advert & - & - & - & - & - & - & - \\
\hline
\end{tabular}

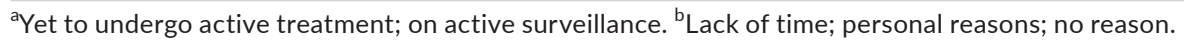

\subsection{4 | Religious organisations}

In light of the high rate of those who attend church services within the Black community (Akhazemea, 2015; TEARFUND, 2007), the church was also considered as a potential avenue to access participants for the study. The leaders of three churches (same denomination but located at different areas with dense Black populations across England) were contacted to discuss the possibility of recruitment within their congregation. Using a poster, church leaders were asked to help create an awareness about the study. The option of having the researcher come and introduce the study to their congregation was also discussed. Despite these approaches, efforts to pursue recruitment further after these initial discussions proved difficult.

\subsection{5 | National health service hospital trusts}

Recruitment was further explored by collaborating with three NHS hospital Trusts based in London. A consultant urological surgeon, an uro-oncology clinical nurse specialist and research nurses who cared for patients with $\mathrm{CaP}$ all helped to expedite access to potentially eligible patients at their respective hospitals. Following ethical approval, the HCPs at each of the hospitals made the initial contact with eligible patients and provided the study information sheet. The consent procedure for eligible patients was agreed with each of the HCPs in line with their Trust's internal procedures and policies.

\subsection{6 | Snowball sampling}

Participating men who had partners were asked to help inform them (partners) about the study or with their partners' permission, the researcher contacted them directly to discuss the study. The participating men were also asked to refer any other known eligible BA/BC men with $\mathrm{CaP}$ to the researcher. Although some participants knew about other potentially eligible men, they stated they could not refer them to the study because they did not want to disclose their own illness to others and mentioning the research to them (potential participants) could compromise this stance.

\section{3 | RESULTS}

\section{1 | Overview}

A detailed description of our recruitment strategies and outcomes is presented in Table 2. The contact details of 52 potential participants (men $=41$; partners $=11$ ) were received across the various recruitment strategies. From these, 45 participants (men $=34$; partners $=11$ ) were successfully contacted. Seven men could not be contacted because they were unreachable by phone and did not respond to the invitation letter and information pack sent by post. Three men with CaP were deemed ineligible (two were on active surveillance and it was less than three months since one had undergone active treatment) whilst six declined to participate. In total, 36 eligible participants (men $=25$, partners $=11$ ) agreed to participate in the study and were interviewed. The demographic details of participants are presented in Table 3. The majority of the participants preferred face-to-face interviews ( $n=29,81 \%$ ). Due to geographical and time limitations, two participants (man and partner) were happy to be interviewed by telephone whilst the remaining five were interviewed by Skype. Participating in a qualitative study was a new experience for the majority of the men and partners and many of them viewed their participation as an avenue to share their experiences to "help others" on their CaP journey.

\subsection{1 | Reasons given for non-participation}

For those six men who declined to participate, none expressed any ethical concerns regarding the conduct of the study. Two men were unable to find time for a face-to-face interview and were not willing to consider a telephone or Skype interview. Although three men did 
not formally decline participation, after few unsuccessful attempts at contacting them, their silence was taken as a refusal and no further contact was made. One participant gave personal reasons for declining to participate and his decision was respected.

\section{2 | Recruitment outcomes}

The projected sample size of 30 participants was exceeded and theoretical saturation was achieved. However, some strategies were more successful than others for recruiting participants into the study. Although statistical analysis was not conducted to measure the effectiveness of each strategy, it was considered necessary to highlight how they individually contributed towards recruitment. We defined strategies which mostly contributed towards the achievement of our recruitment target as successful whilst those which recruited only one or no participant at all were regarded as unsuccessful.

\subsection{1 | Successful strategies}

Collaborating with NHS hospital Trusts and snowball sampling were the most successful strategies, yielding 64\% ( $n=23)$ and $25 \%$ $(n=9)$ of the total participants recruited respectively (Table 2). For the men group, the majority (80\%) were recruited through the three NHS hospitals whilst the majority of partners (63\%) were recruited by snowball sampling through their participating husbands (Table 2). Two men were also recruited by snowballing through their friends who had already participated in the study. Colleagues, and researchers' networks also yielded three participants (men $=2$, partner $=1$ ).

TAB LE 3 Ethnic representation of study participants

\begin{tabular}{|c|c|c|}
\hline & $\begin{array}{l}\text { Men } \\
n(\%)\end{array}$ & $\begin{array}{l}\text { Partners } \\
n(\%)\end{array}$ \\
\hline \multicolumn{3}{|l|}{ Black African (11) } \\
\hline Nigeria & $2(8)$ & $1(9)$ \\
\hline Ghana & $4(16)$ & $2(18)$ \\
\hline Sierra Leone & $2(8)$ & - \\
\hline \multicolumn{3}{|l|}{ Black Caribbean (21) } \\
\hline Jamaica & $8(32)$ & $2(18)$ \\
\hline Barbados & $4(16)$ & $2(18)$ \\
\hline Guyana & $1(4)$ & - \\
\hline Montserrat & $1(4)$ & - \\
\hline St. Lucia & $1(4)$ & - \\
\hline Caribbean Virgin Islands & $1(4)$ & - \\
\hline Dominica & $1(4)$ & - \\
\hline \multicolumn{3}{|l|}{ White (4) } \\
\hline British & - & $2(18)$ \\
\hline Irish & - & $1(9)$ \\
\hline Spanish & - & $1(9)$ \\
\hline Total $(n=36)$ & $25(69)$ & $11(31)$ \\
\hline
\end{tabular}

\subsection{2 | Unsuccessful strategies}

Despite contacting 33 support groups, only one man was recruited into the study via this strategy (Table 2). No partner was identified nor recruited from the support groups. The researchers' experience with the support groups showed that although some gatekeepers were willing, others were less enthusiastic in enabling access to potentially eligible members within their group. Some were slow to respond to emails or phone calls, and some requested non-negotiable and/or substantial payment as a prerequisite for informing their members about the research. Such payment demands could not be met due to limited finances available for this research. The media advertisement and religious organisations did not yield any eligible participants for this study. It had been anticipated that the first author's personal network with religious leaders could yield potential eligible members of their churches, but such attempts were not successful. After the initial face-to-face discussions, there were long delays in responding to follow-up emails and telephone calls.

\section{4 | DISCUSSION}

Recruitment outcomes varied among the different strategies used to recruit 'hard to reach' $\mathrm{BA}$ and $\mathrm{BC}$ men with $\mathrm{CaP}$ and their partners into this qualitative study. The barriers and facilitators to successful recruitment of participants for this study will now be discussed.

\section{1 | Barriers}

In addition to a few participants declining to participate for reasons highlighted earlier, additional barriers were encountered which limited recruitment for this study. These are categorised as actual and perceived barriers. Actual barriers were those encountered during fieldwork for this study and included "gatekeeping issues" and "stigma associated with prostate cancer disclosure." The perceived barrier was the researchers' perception of an additional limitation to recruitment as informed by a reflection on our recruitment experience. This included "limited advertisement."

\subsection{1 | Gatekeeping issues}

Similar to findings from a review by Bonevski et al. (2014), gatekeeping emerged as an actual barrier to recruiting participants from the support groups and religious organisations approached. Gatekeepers at many of the support groups and religious organisations restricted access to potentially eligible members. As a result, members did not have the opportunity to make their own decision about participating. Where men were the gatekeepers to accessing their partners, some declined their partner's participation noting that the women preferred to "operate behind the scene" than engage in research participation. Hence such men did not give their partners the opportunity to make their own informed decision to participate or not. 
Whilst acknowledging the autonomous power of gatekeepers at support groups and religious organisations to either hinder or promote access to their members or contacts (Singh \& Wassenaar, 2016), there is need to also consider how this may possibly impact on the voluntary rights of potential participants to personally decide their participation or otherwise in a research study (Mamotte \& Wassenaar, 2017; Wanat, 2008). Experience with participants in this study suggests that they may be willing to participate in research studies if they are asked, as many of them seemed to view their participation as a way of "helping others." Although the researcher offered to volunteer at one of the support groups approached and all the support groups were also told they would be provided with summary of research findings as an "incentive" for their cooperation (Singh \& Wassenaar, 2016), this strategy remained unsuccessful for the current study.

Some gatekeepers at support groups with high BAs/BCs were also unwilling to inform their members about the study unless the researchers met certain prerequisite payment demands to cover interviewing costs and provide incentives for participating members. Such payment demands could not be met due to limited funds available to complete this academic research. The researcher also clarified to the gatekeepers that participants would not be burdened with travel or financial costs as the researcher would meet with them at their preferred location. However, such explanations were not productive. Debates exist regarding the ethical implications of incentivising research participation on participant's autonomy (Collins et al., 2017; Polacsek, Boardman, \& McCann, 2017). Whilst some studies (Faseru et al., 2010; George, Duran, \& Norris, 2014) have reported giving of incentives encouraged research participation among their African American participants, others argued (Toms et al., 2016) that incentives may be perceived as suspicious and debar BA and $\mathrm{BC}$ men with $\mathrm{CaP}$ from participating in clinical research. Rivas, Kelly, and Feder (2013) suggest that informing participants of incentives at their interviews, without any prior knowledge could help reduce suspicion and potentially encourage voluntariness in research participation. Since potential participants at support groups were not informed about the study, it is unclear how incentivising the research may have influenced their personal decision to participate in this qualitative study or not. Arguably, some gatekeepers may be regarded as having an experiential understanding of how best to engage their members in research participation. However, there is need to consider the peculiar nature of each study and allow members the personal autonomy to accept or decline research invitations regardless of the presence or absence of financial incentives.

Previous studies involving Black populations (e.g., Nanton \& Dale, 2011; Bamidele, Ali, Papadopoulos, \& Randhawa, 2017) had successfully recruited participants through religious settings. However, it appeared because of other duties taking precedence, discussing the study among their congregational members was not viewed as a priority for the church leaders who were approached. It was also perceived that the delicate nature of being diagnosed with $\mathrm{CaP}$ may have further contributed to the church leaders' reluctant attitude towards this study. Prior evidence (Sheikh et al., 2009) suggested a gap in knowledge among religious leaders regarding the importance of research and their influence in encouraging research participation among their members. It is envisaged that better outcomes may have been achieved if recruitment was explored across different religious settings (e.g., other churches, mosques) and denominations over a longer period of time, but this could not be achieved in the current study due to a limited time frame.

\subsection{2 | Stigma associated with prostate cancer disclosure}

Some participants' (men) reluctance to refer other eligible men to the study was an actual barrier to recruitment. The men attributed this to protecting non-disclosure of their $\mathrm{CaP}$ diagnosis within their wider social circle (including friends and religious affiliations). Nondisclosure was mostly attributed to perceptions of self and social stigma associated with being diagnosed with $\mathrm{CaP}$ within the BA/ $B C$ cultural setting. This supports existing evidence that cultural perceptions of $\mathrm{CaP}$ (such as fatality, emasculating) often impact on Black men's attitudes and behaviours towards public disclosure of the disease (Kendrick, 2010; Mulugeta et al., 2017; Pedersen, Armes, \& Ream, 2012; Rivas et al., 2016). Nevertheless, Nanton and Dale (2011) successfully recruited Jamaican men with CaP through the church, personal contacts of their interviewers and the local community. Conflicting recruitment outcomes between this current study and Nanton and Dale's (2011) suggest that similar strategies may not necessarily generate the same outcomes even for similar studies and target populations.

\subsection{3 | Limited advertisement}

Recruitment through media adverts was perceived to have been impeded by limited advertisement as the research was advertised on only two radio stations for one month. This was substantially due to financial constraints to cover the associated costs of extending advertisement to other media channels with wider coverage areas and for much longer. Upon reflection, it was perceived that complementing extensive radio advertisement with other media channels such as television, newspapers with a wider focus on Black audience may have improved our recruitment outcome via this strategy (Graham, Lopez-Class, Mueller, Mota, \& Mandelblatt, 2011), especially from within the community.

\section{2 | Facilitators}

Recruitment success was aided by a number of factors which were also classified as actual and perceived facilitators. The actual facilitators which emerged from fieldwork as informed by our recruitment outcomes included "collaborating with NHS hospital Trusts," "snowball sampling" and "flexibility in data collection modes." Upon reflection on our experience during fieldwork, recruitment also seemed to have been facilitated by "building rapport with participants to gain their trust" and "researcher's attributes." 


\subsection{1 | Collaborating with National Health Service hospital Trusts}

Consistent with the study of Anderson et al. (2013) in which all their $\mathrm{BA}$ and $\mathrm{BC}$ participants were recruited through the hospital, collaborating with $\mathrm{NHS}$ hospitals emerged as the most successful strategy for recruiting men into this study as $80 \%$ of them were recruited via this means. Lyons et al. (2013) suggested that using gatekeepers with whom participants are familiar could improve access to culturally diverse populations. HCPs' goodwill and rapport with their patients further enhanced recruitment in the current study as some participants spontaneously commented on these during their interviews. Patients being reassured by a HCP that the study had received ethical approval and that participation would not affect their care in any way, may have promoted men's confidence in the authenticity of the research (Anderson et al., 2009). Although complex ethical application processes often limit researchers' abilities to access "hard to reach" patients within limited time and financial resources, the interest and support shown by the HCPs facilitated the process of seeking ethical approval. To retain the interest and support of the HCPs, they were constantly updated on the progress of the study.

\subsection{2 | Snowball sampling}

Using snowball sampling facilitated recruitment of partners into the study. The majority of partners (63\%) were recruited through their participating husbands. Snowball sampling thrives on the use of personal relationship networks to access participants who otherwise may not have been aware of, or participated in a study (Etikan, Alkassim, \& Abubakar, 2016; Wohl et al., 2017). Although prone to selection bias which may result from over-representation of members of a particular participant's network (Etikan et al., 2016), snowball sampling has been widely acknowledged as useful in promoting research participation among "hard to reach" populations in a costeffective and timely manner (Richards \& Morse, 2007; Sadler, Lee, Lim, \& Fullerton, 2011; Wohl et al., 2017). Nanton and Dale (2011) successfully used snowball sampling to recruit African-Caribbean men with $\mathrm{CaP}(n=16)$ into their qualitative study. Whilst this strategy enhanced successful recruitment in their study, it appeared to have contributed to the selection bias observed in the study leading to a homogenous sample of Jamaican men (Nanton \& Dale, 2011). The risk of selection bias often associated with snowball sampling was minimised in this study by complementing it with additional recruitment strategies (Etikan et al., 2016).

\subsubsection{Flexibility in data collection mode}

As similarly reported by Shedlin, Decena, Mangadu, and Martinez (2011), using flexible data collection modes also enhanced recruitment for this study. Participants had options to be interviewed either face-to-face, by telephone or via Skype. The majority of participants ( $n=29 ; 81 \%$ ) preferred to be interviewed face-to-face in their natural environments (homes and private office). Interviewing participants in their own familiar and relaxed environments enhanced data collection and without them experiencing any travel or financial burden (Bryman, 2012). Noting the perceived delicate nature of their illness experiences, especially where there would be discussions around sexual function (Anyan, 2013; Szolnoki \& Hoffmann, 2013), it was understandable that the majority of our participants preferred faceto-face interviews.

Given the distant geographical location of some participants, they opted to be interviewed by Skype when offered. With improvements in technology, Skype interviews now provide a useful alternative to face-to-face interviews by helping to bridge distance barriers, reduce travel risks and minimise costs (Deakin \& Wakefield, 2014). Although evidence shows that Skype interviews could be prone to technological distractions, less rapport building and reduced clarity in audio-recordings which could impact on data quality (Janghorban, Latifnejad, \& R. and Taghipour, A., 2014), it was used successfully in this study. Having a video facility within Skype was also useful to help to capture non-verbal clues during the interviews (Janghorban et al., 2014). Likewise, potential undesirable technological interferences and poor audio recording quality which could occur during Skype interviews were mitigated by the researcher's and participants' familiarity with technology and by ensuring that interviews were scheduled for times and places with uninterrupted Internet access (Deakin \& Wakefield, 2014). Where acceptable by their participants, future studies may also explore the use of Skype as a proficient alternative to overcome cost and distance barriers associated with face-to-face interviews. This could help ensure that participants recruited into the study are promptly interviewed without jeopardising rapport building.

\subsection{4 | Building rapport with participants to gain their trust}

Establishing trust with potential participants through rapport building was perceived to also have enhanced successful recruitment for this study. To facilitate rapport, the same researcher (OB) followed them from recruitment to conducting their interviews. This seemed to help create a sense of familiarity with participants and encouraged a high retention rate as all the participants recruited were successfully interviewed. There were also indications that using face-to-face interviews, coupled with the interviewer's (OB) ethnicity as BA may have further enhanced rapport building with study participants as many of them seemed to identify with her as an "insider" (Fassinger and Morrow (2013). Some studies highlight the importance of ethnically matching interviewers with ethnic minority participants as a way of showing cultural sensitivity and promoting shared identity to improve research engagement with them (Anderson et al., 2009; Nanton \& Dale, 2011; Rugkåsa \& Canvin, 2011). However, relevant theories such as the intersectionality theory (Crenshaw, 1989) argue that study participants' perceptions of the researcher as either an "insider" or an "outsider" is oftentimes not solely influenced by a shared cultural identity related to race and ethnicity only, but by an intersection between these factors (race 
and ethnicity) and other wider factors such as gender, age and sexuality. Katigbak, Foley, Robert, and Hutchinson (2016) also insist that shared ethnicity between researchers and their study participants does not necessarily imply shared experience. Nash (2008) further identified the importance of the intersectionality theory in facilitating a conceptual understanding of the complexities around "insider/ outsider" status in research relationships especially when studying marginalised populations.

\subsection{5 | Researcher's attributes}

Evidence suggests that the researcher's attributes could impact on recruitment and research participation especially among BME populations (Hoppitt et al., 2012; Sheikh et al., 2009). It had been anticipated that the researcher's gender and age as a young female in her mid-thirties may have potentially imposed an "outsider" status which could limit recruitment and quality data collection from older BA/BC men on a sensitive male-focused subject such as CaP (Braun \& Clarke, 2013; Khambhaita, Willis, Pathak, \& Evandrou, 2017). However, none of the study participants expressed any concerns regarding this as they freely shared their stories (including the "sensitive" sexual aspects of their experiences).

This resonates with evidence from previous studies which had successfully used female researchers to interview Caucasian (McCaughan et al., 2015) and Black (Anderson et al., 2013) men with CaP. Fergus, Gray, and Fitch (2002) highlighted that most of the male participants in their study expressed preference to be interviewed by a female researcher when they were offered choices between a male or female interviewer. This suggests that the researcher's gender or age may be less important in research relationships with Black men with $\mathrm{CaP}$ especially where such researchers are experienced in conducting qualitative interviews. Moreover, complementing her previous experience of successful research engagement with BA populations with her ethnicity as BA enhanced the researcher's ability to build mutual understanding with study participants. The PPI group also suggested that providing information to participants to aid their understanding of the purpose of the scientific study has the potential to reduce barriers associated with gender differences between a female researcher and male study participants.

\section{3 | Implications for practice}

The recruitment challenges experienced in this study are not peculiar to $\mathrm{BA}$ and $\mathrm{BC}$ men with $\mathrm{CaP}$ and their partners. Previous research which involved other "hard to reach" (e.g., victims of abuse [Rivas et al., 2013]) and vulnerable populations (e.g., people with a learning disability [Carey \& Griffiths, 2017]) have reported similar challenges when trying to recruit participants. However, findings from this study highlight that amidst shared similarities in recruitment barriers, there is no "one size fits all" approach to navigating such challenges. There is need for researchers to be dynamic and understand the specific characteristics of their target populations whilst considering the nature of their research in order to tailor their recruitment approaches. For example, the perceptions of stigma associated with $\mathrm{CaP}$ within the $\mathrm{BA}$ and $\mathrm{BC}$ communities which impact on their attitude towards their illness disclosure highlight the importance of involving their healthcare providers in the recruitment plan for this study. In addition to gatekeeping issues when recruiting $\mathrm{BA} / \mathrm{BC}$ men with $\mathrm{CaP}$ and partners, due considerations should also be given to time and cost implications. Furthermore, there is need for researchers to respect the terms and conditions stipulated by support groups to access their members. For example, physically meeting with gatekeepers and fulfilling stipulated payment demands may have advanced better recruitment outcomes from the support groups contacted in this study. Nevertheless, it is essential that researchers remain realistic in their recruitment expectations in terms of the number of participants they can recruit within the allocated resources for a study.Gatekeepers at support groups also need to be aware of the ethical implications of withholding research information from their members and how this may potentially contribute to their (members') marginalisation in emerging evidence. It is essential that gatekeepers ensure that their members are given an opportunity to make their own decision regarding participation in studies once ethical considerations have been applied. Whilst the religious organisation approached for this study was not particularly productive for recruitment, prior evidence highlights that religious organisations continue to be potential avenues for recruiting Black populations into research studies (Bamidele, Ali, et al., 2017; Nanton $\&$ Dale, 2011). Researchers should continue to engage with religious leaders, increasing their awareness on the potential benefits of research participation and encourage their cooperation in helping to enable access to interested and eligible members where appropriate. Evidence from this study supports previous suggestions (Newington $\&$ Metcalfe, 2014) that research participation can be enhanced if patients are informed about the study by their main HCPs. This further suggests the need for future researchers to continue to liaise with HCPs who are the men's primary care givers in order to improve recruitment outcomes for their studies.

\subsection{Study limitations and directions for future research}

In contrast to previous related studies (Anderson et al., 2013; Nanton \& Dale, 2011), the recruitment of a more heterogeneous sample of "hard to reach" BA/BC men with CaP into the current study was facilitated by collaborating with NHS hospital staff. Recruitment of partners was also enhanced by snowballing through their husbands who participated in the study. However, the actual response rate for the study could not be assessed because the overall number of participants who were approached were not recorded by the HCPs (e.g., potential participants who may have possibly declined participation at the point of being informed about the study by an HCP without the researcher receiving their contact details). Although statistical calculations such as response rates are less significant in qualitative studies like this, we 
acknowledge that the success or otherwise of the different strategies used are subjective to our particular recruitment experience and cannot be generalised. Future papers on recruitment should endeavour to apply statistical measures to their response rates in order to enhance a more rigorous assessment of their recruitment outcomes, especially for larger quantitative studies. Future studies could also explore from gatekeepers' perspectives, their experiences with researchers and the challenges of promoting research participation among their BA/BC members. This could help to provide a more balanced understanding of recruitment challenges and how such can be more effectively addressed in order to improve research engagement with "hard to reach" groups.

\section{5 | CONCLUSION}

Little is known from the researcher's perspective about the barriers and facilitators to recruiting high risk yet under-researched BA and BC men with $\mathrm{CaP}$ and their partners into qualitative research. This paper has contributed towards reducing this knowledge gap. Collaborating with NHS hospital Trusts and snowballing through participating men were the most successful strategies for recruiting men and partners respectively into this study. Support groups, media advertisement and religious organisation were less successful recruitment strategies. Researchers' experiences in this study indicate that BA and BC populations may be "hard to reach" but they are not "out of reach" if flexible, strategic and culturally sensitive recruitment approaches are used.

\section{ACKNOWLEDGEMENTS}

The current study is supported by a vice-chancellor's research scholarship to OB for her PhD. Our sincere gratitude goes to the supportive HCPs and their respective NHS hospital Trusts for assisting with recruiting patients for this study. The authors wish to thank the support groups which granted access to their members for this study and those who offered helpful suggestions regarding recruitment. We would also like to thank Dr Veronica Nanton, Michelle O-King, Suresh Rambaran, Anita Mehay and other colleagues for their kind effort and helpful suggestions on how to recruit participants for this study. Finally, we sincerely appreciate all the men and partners who participated in this study and made our recruitment effort worthwhile and productive.

\section{ORCID}

Olufikayo O. Bamidele (D) https://orcid.org/0000-0003-2235-9463

Helen E. McGarvey (D) https://orcid.org/0000-0001-9145-8778

Briege M. Lagan (ID https://orcid.org/0000-0001-5536-394X

\section{REFERENCES}

Akhazemea (2015). The reshaping of religious and social landscape of Britain: The influence of the black majority churches. Retrieved from https://www.biblesociety.org.uk/uploads/content/bible_in_transmission/files/2015_spring/BiT_Spring_2015_Akhazemea.pdf (accessed 1 November, 2017).

Anderson, B., Marshall-Lucette, S., \& Webb, P. (2013). African and AfroCaribbean men's experiences of prostate cancer. British Journal of Nursing, 22(22), 1296-1307, 12p. https://doi.org/10.12968/ bjon.2013.22.22.1296

Anderson, M., Solarin, I., Gerver, S., Elam, G., MacFarlane, E., Fenton, K., \& Easterbrook, P. (2009). Research Note: The LIVITY study: Research challenges and strategies for engaging with the black Caribbean community in a study of HIV infection. International Journal of Social Research Methodology, 12, 197-209. https://doi. org/10.1080/13645570701708584

Anyan, F. (2013). The influence of power shifts in data collection and analysis stages: A focus on qualitative research interview. The Qualitative Report, 18, 1.

Bamidele, O., Ali, N., Papadopoulos, C., \& Randhawa, G. (2017). Exploring factors contributing to low uptake of the NHS breast cancer screening programme among black African women in the UK. Diversity and Equality in Health and Care, 14, 212-219.

Bamidele, O., McGarvey, H., Lagan, B., Ali, N., Chinegwundoh, M., Parahoo, K., \& McCaughan, E. (2017). Life after prostate cancer: A systematic literature review and thematic synthesis of the post-treatment experiences of Black African and Black Caribbean men. European Journal of Cancer Care, 27(1), e12784. https://doi. org/10.1111/ecc.12784.

Bonevski, B., Randell, M., Paul, C., Chapman, K., Twyman, L., Bryant, J., ... Hughes, C. (2014). Reaching the hard-to-reach: A systematic review of strategies for improving health and medical research with socially disadvantaged groups. BMC Medical Research Methodology, 14, 42. https://doi.org/10.1186/1471-2288-14-42

Braun, V., \& Clarke, V. (2013). Successful qualitative research: A practical guide for beginners. London: Sage.

Bryman, A. (2012). Social research methods, 4th ed. Oxford, UK: Oxford University Press.

Carey, E., \& Griffiths, C. (2017). Recruitment and consent of adults with Intellectual disabilities in a classic grounded theory research study: Ethical and methodological considerations. Disability \& Society, 32, 193-212. https://doi.org/10.1080/09687599.2017.1281793.

Collins, A. B., Strike, C., Guta, A., Turje, R. B., McDougall, P., Parashar, S., \& McNeil, R. (2017). "We're giving you something so we get something in return": Perspectives on research participation and compensation among people living with HIV who use drugs. International Journal of Drug Policy, 39, 92-98.

Crenshaw, K. (1989). Demarginalizing the intersection of race and sex: A black feminist critique of antidiscrimination doctrine, feminist theory and antiracist politics. University of Chicago Legal Forum, 139.

Deakin, H., \& Wakefield, K. (2014). Skype interviewing: Reflections of two PhD researchers. Qualitative Research, 14, 603-616. https://doi. org/10.1177/1468794113488126

Etikan, I., Alkassim, R., \& Abubakar, S. (2016). Comparison of Snowball Sampling and Sequential Sampling Technique. Biometrics and Biostatistics International Journal, 3, 00055.

Faseru, B., Cox, L. S., Bronars, C. A., Opole, I., Reed, G. A., Mayo, M. S., ... Okuyemi, K. S. (2010). Design, recruitment, and retention of African-American smokers in a pharmacokinetic study. BMC Medical Research Methodology, 10, 6. https://doi. org/10.1186/1471-2288-10-6

Fassinger, R., \& Morrow, S. (2013). Toward best practices in quantitative, qualitative, and mixed-method research: A social justice perspective. Journal for Social Action in Counseling and Psychology, 5, 69-83.

Fergus, K. D., Gray, R. E., \& Fitch, M. I. (2002). Sexual dysfunction and the preservation of manhood: Experiences of men with prostate cancer. Journal of Health Psychology, 7, 303-316. https://doi. org/10.1177/1359105302007003223 
Foley, G., \& Timonen, V. (2015). Using grounded theory method to capture and analyze health care experiences. Health Services Research, 50, 1195-1210. https://doi.org/10.1111/1475-6773.12275

George, S., Duran, N., \& Norris, K. (2014). A systematic review of barriers and facilitators to minority research participation among African Americans, Latinos, Asian Americans, and Pacific Islanders. American Journal of Public Health, 104, e16-e31. https://doi.org/10.2105/ AJPH.2013.301706

Graham, A. L., Lopez-Class, M., Mueller, N. T., Mota, G., \& Mandelblatt, J. (2011). Efficiency and cost-effectiveness of recruitment methods for male Latino smokers. Health Education \& Behavior, 38, 293-300. https://doi.org/10.1177/1090198110372879

Gray, R. E., Fergus, K. D., \& Fitch, M. I. (2005). Two Black men with prostate cancer: A narrative approach. British Journal of Health Psychology, 10(1), 71-84, 14p. https://doi.org/10.1348/135910704X14429

Hoppitt, T., Shah, S., Bradburn, P., Gill, P., Calvert, M., Pall, H., ... Sackley, C. (2012). Reaching the 'hard to reach': Strategies to recruit black and minority ethnic service users with rare long-term neurological conditions. International Journal of Social Research Methodology, 15, 485-495. https://doi.org/10.1080/17522439.2011.615161

Hosseinpoor, A. R., Williams, J., Itani, L., \& Chatterji, S. (2012). Socioeconomic inequality in domains of health: Results from the world health surveys. BMC Public Health, 12, 1-13. https://doi. org/10.1186/1471-2458-12-198

Janghorban, R., Roudsari, R. L., \& Taghipour, A. (2014). Skype interviewing: The new generation of online synchronous interview in qualitative research. International Journal of Qualitative Studies on Health and Well-being, 9, 24152. https://doi.org/10.3402/qhw. v9.24152.

Jones, A. L., \& Chinegwundoh, F. (2014). Update on prostate cancer in black men within the UK. Ecancermedicalscienc, 8, 455-455.

Jones, C. E., Maben, J., Jack, R. H., Davies, E. A., Forbes, L. J., Lucas, G., \& Ream, E. (2014). A systematic review of barriers to early presentation and diagnosis with breast cancer among black women. British Medical Journal Open, 4, e004076. https://doi.org/10.1136/ bmjopen-2013-004076

Katigbak, C., Foley, M., Robert, L., \& Hutchinson, M. K. (2016). Experiences and lessons learned in using community-based participatory research to recruit Asian American immigrant research participants. Journal of Nursing Scholarship, 48, 210-218. https://doi. org/10.1111/jnu.12194

Kendrick, R. D. (2010). Erectile dysfunction: A barrier to prostate cancer screening among African American men. Capella University.

Khambhaita, P., Willis, R., Pathak, P., \& Evandrou, M. (2017) Recruitment of South Asian research participants and the challenges of ethnic matching: age, gender and migration history. Centre for Research on Ageing, 1701.

Lyons, H. Z., Bike, D. H., Ojeda, L., Johnson, A., Rosales, R., \& Flores, L. Y. (2013). Qualitative research as social justice practice with culturally diverse populations. Journal for Social Action in Counseling and Psychology, 5, 10-25.

Mamotte, N., \& Wassenaar, D. (2017). Voluntariness of consent to HIV clinical research: A conceptual and empirical pilot study. Journal of Health Psychology, 22, 1387-1404. https://doi. org/10.1177/1359105316628737

Marmot, M. G., Allen, J., Goldblatt, P., Boyce, T., McNeish, D., Grady, M., \& Geddes, I. (2010). Fair society, healthy lives: Strategic review of health inequalities in England post-2010. London, UK: The Marmot Review.

McCaughan, E., McKenna, S., McSorley, O., \& Parahoo, K. (2015). The experience and perceptions of men with prostate cancer and their partners of the CONNECT psychosocial intervention: A qualitative exploration. Journal of Advanced Nursing, 71, 1871-1882. https://doi. org/10.1111/jan.12648

Mulugeta, B., Williamson, S., Monks, R., Hack, T., \& Beaver, K. (2017). Cancer through black eyes-The views of UK based black men towards cancer: A constructivist grounded theory study. European
Journal of Oncology Nursing, 29, 8-16. https://doi.org/10.1016/j. ejon.2017.04.005

Nanton, V., \& Dale, J. (2011). It don't make sense to worry too much': The experience of prostate cancer in African-Caribbean men in the UK. European Journal of Cancer Care, 20, 62-71.

Nash, J. C. (2008). Re-thinking intersectionality. Feminist Review, 89, 115. https://doi.org/10.1057/fr.2008.4

National Institute for Health and Care Excellence (2015). Prostate Cancer. Retrieved from http://www.nice.org.uk/guidance/qs91/chapter/ Quality-statement-4-Managing-adverse-effects-of-treatment (accessed 1 November, 2017).

Newington, L., \& Metcalfe, A. (2014). Factors influencing recruitment to research: Qualitative study of the experiences and perceptions of research teams. BMC Medical Research Methodology, 14, 10. https://doi. org/10.1186/1471-2288-14-10

Office for National Statistics (2012) Ethnicity and National Identity in England and Wales 2011. Retrieved from http://ons.gov.uk/ons/ dcp171776_290558.pdf (accessed 1 November, 2017).

O'Shaughnessy, P. K., Ireland, C., Pelentsov, L., Thomas, L. A., \& Esterman, A. J. (2013). Impaired sexual function and prostate cancer: A mixed method investigation into the experiences of men and their partners. Journal of Clinical Nursing, 22, 3492-3502. https://doi.org/10.1111/ jocn.12190

Pedersen, V. H., Armes, J., \& Ream, E. (2012). Perceptions of prostate cancer in Black African and Black Caribbean men: A systematic review of the literature. Psycho-oncology, 21, 457-468. https://doi. org/10.1002/pon.2043

Pinder, R. J., Ferguson, J., \& Moller, H. (2016). Minority ethnicity patient satisfaction and experience: Results of the National Cancer Patient Experience Survey in. England. BMJ Open, 6, e011938. https://doi. org/10.1136/bmjopen-2016-011938

Polacsek, M., Boardman, G., \& McCann, T. V. (2017). Paying patient and caregiver research participants: Putting theory into practice. Journal of Advanced Nursing, 73, 847-856. https://doi.org/10.1111/ jan.13222

Richards, L., \& Morse, J. M. (2007). README FIRST for a user's guide to qualitative research, 2 nd ed. London, UK: Sage.

Rivas, C., Kelly, M., \& Feder, G. (2013). Drawing the line: How African, Caribbean and white British women live out psychologically abusive experiences. Violence against Women, 19, 1104-1132. https://doi. org/10.1177/1077801213501842

Rivas, C., Matheson, L., Nayoan, J., Glaser, A., Gavin, A., Wright, P., .. Watson, E. (2016). Ethnicity and the prostate cancer experience: A qualitative metasynthesis. Psycho-oncology, 25, 1147-1156.

Rivers, B. M., August, E. M., Gwede, C. K., Hart, A., Donovan, K. A., Pow-Sang, J. M., \& Quinn, G. P. (2011). Psychosocial issues related to sexual functioning among African-American prostate cancer survivors and their spouses. Psycho-Oncology, 20, 106-110. https://doi. org/10.1002/pon.1711

Rivers, B. M., August, E. M., Quinn, G. P., Gwede, C. K., Pow-Sang, J. M., Green, B. L., \& Jacobsen, P. B. (2012). Understanding the psychosocial issues of African American couples surviving prostate cancer. Journal of Cancer Education, 27, 546-558. https://doi.org/10.1007/ s13187-012-0360-1

Rugkåsa, J., \& Canvin, K. (2011). Researching mental health in minority ethnic communities: Reflections on recruitment. Qualitative Health Research, 21, 132-143. https://doi.org/10.1177/1049732310 379115

Sadler, G., Lee, H., Lim, R., \& Fullerton, J. (2011). Recruiting hard-to-reach United States populations sub-groups via adaptations of snowball sampling strategy. Nursing Health Science, 12, 369-374.

Shedlin, M. G., Decena, C. U., Mangadu, T., \& Martinez, A. (2011). Research participant recruitment in Hispanic communities: Lessons learned. Journal of Immigrant and Minority Health, 13, 352-360. https://doi.org/10.1007/s10903-009-9292-1 
Sheikh, A., Halani, L., Bhopal, R., Netuveli, G., Partridge, M. R., Car, J., ... Levy, M. (2009). Facilitating the recruitment of minority ethnic people into research: Qualitative case study of South Asians and asthma. PLoS Medicine, 6, e1000148. https://doi.org/10.1371/journal.pmed.1000148

Singh, S., \& Wassenaar, D. (2016). Contextualising the role of the gatekeeper in social science research. South African Journal of Bioethics and Law, 9, 42-46. https://doi.org/10.7196/SAJBL.2016.v9i1.465

Speer, S. A., Tucker, S. R., McPhillips, R., \& Peters, S. (2017). The clinical communication and information challenges associated with the psychosexual aspects of prostate cancer treatment. Social Science \& Medicine, 185, 17-26. https://doi.org/10.1016/j. socscimed.2017.05.011

Sydor, A. (2013). Conducting research into hidden or hard-to-reach populations. Nurse Researcher, 20, 33-37. https://doi.org/10.7748/ nr2013.01.20.3.33.c9495

Szolnoki, G., \& Hoffmann, D. (2013). Online, face-to-face and telephone surveys-Comparing different sampling methods in wine consumer research. Wine Economics and Policy, 2, 57-66. https://doi. org/10.1016/j.wep.2013.10.001

TEARFUND (2007). Churchgoing in the UK. Retrieved from http://news. bbc.co.uk/1/shared/bsp/hi/pdfs/03_04_07_tearfundchurch.pdf (accessed 1 November, 2017).
Toms, C., Cahill, F., George, G., \& Van Hemelrijck, M. (2016). Research engagement among black men with prostate cancer. Ecancermedicalscience, 10, 695. https://doi.org/10.3332/ ecancer.2016.695

Wanat, C. L. (2008). Getting past the gatekeepers: Differences between access and cooperation in public school research. Field Methods, 20, 191-208. https://doi.org/10.1177/1525822X07313811

Wohl, A. R., Ludwig-Barron, N., Dierst-Davies, R., Kulkarni, S., Bendetson, J., Jordan, W., ... Perez, M. J. (2017). Project engage: snowball sampling and direct recruitment to identify and link hard-to-reach HIVinfected persons who are out of care. Journal of Acquired Immune Deficiency Syndromes (1999), 75, 190-197.

How to cite this article: Bamidele OO, McGarvey HE, Lagan BM, Chinegwundoh F, Ali N, McCaughan E. "Hard to reach, but not out of reach": Barriers and facilitators to recruiting Black African and Black Caribbean men with prostate cancer and their partners into qualitative research. Eur J Cancer Care. 2018;e12977. https://doi.org/10.1111/ecc.12977 